\title{
The Concepts of Modularization in ICT Service Modeling
}

\author{
Schorr, Franziska; Hvam, Lars
}

Published in:

Proceedings of the 2019 IEEE International Conference on Industrial Engineering and Engineering Management (IEEM)

Link to article, DOI:

10.1109/IEEM44572.2019.8978785

Publication date:

2019

Document Version

Peer reviewed version

Link back to DTU Orbit

Citation (APA):

Schorr, F., \& Hvam, L. (2019). The Concepts of Modularization in ICT Service Modeling. In Proceedings of the 2019 IEEE International Conference on Industrial Engineering and Engineering Management (IEEM) IEEE. https://doi.org/10.1109/IEEM44572.2019.8978785

\section{General rights}

Copyright and moral rights for the publications made accessible in the public portal are retained by the authors and/or other copyright owners and it is a condition of accessing publications that users recognise and abide by the legal requirements associated with these rights.

- Users may download and print one copy of any publication from the public portal for the purpose of private study or research.

- You may not further distribute the material or use it for any profit-making activity or commercial gain

- You may freely distribute the URL identifying the publication in the public portal

If you believe that this document breaches copyright please contact us providing details, and we will remove access to the work immediately and investigate your claim 


\title{
The Concepts of Modularization in ICT Service Modeling
}

\author{
F. Schorr ${ }^{1}$, L. Hvam ${ }^{1}$ \\ ${ }^{1}$ Department of Technology, Management and Economics, Technical University of Denmark, Kongens Lyngby, Denmark
}

(frsc@dtu.dk)

\begin{abstract}
The use of architectures and modularity are key theoretical concepts helping to manage the design of complex products. We propose that those theoretical concepts can also be applied to information and communication technology (ICT) service modeling. Conceptual service models represent how we understand an ICT service's structure, definition, and scope. As service modeling demonstrates resource requirements for ICT service operations, a conceptual model is a prerequisite for knowledge management and competitive advantage, according to the resource-based view of the firm. This explorative case study investigates how the concepts of modularization are represented in conceptual ICT models. We found that ICT service modeling makes use of basic modularity principles such as the modularization of the service components. Without the representation of interfaces, practitioners and researchers may not be able to leverage the suggested benefits of modularity.
\end{abstract}

Keywords - ICT Service, Modularity, ICT Management

\section{INTRODUCTION}

Servitization, service management, and servicefocused management are rising phenomena in academia and practice. ICT management reacts to the current servitization trend by defining customer-oriented ICT services [1] and by adapting standard service management procedures [2]. By definition, an ICT service uses processes, technology assets, activities, functions, key roles, and vendors to contribute to the value creation in companies [3]. The field considers ICT services as complex services [4]. Multiple service design challenges impact ICT service complexity. Such challenges are for example the integration of various technical (hardware and software) and non-technical (processes and people) components, and the variabilities of services design over the service's lifecycle.

Because of the complexity of service design, academia sees a growing demand for using architectural principles such as modularity and conceptual modeling methods focusing on services [5]. Companies have experienced success in complexity reductions while applying these approaches to physical products.

Service modularity is an architectural approach to managing the complexity of services. Tuunanen et al. (2012) define service modularity as a system of components that offers a well-defined functionality via a precisely described interface and with which a modular service is composed, tailored, customized, and personalized [6]. By the use of modularity principles, a service is split up into individual components that can be managed separately and can be combined via known interfaces. Modularity has therefore been acknowledged principles to reduce service complexity [5].

Companies that successfully apply modularity use a conceptual product model. The conceptual model allows the reuse of design knowledge and principles within the product portfolio. The product design literature presents mature procedures for the conceptual modeling of modular products, for example, Hvam et al. (2017) [7]. In comparison to the product design literature, the service science literature is lacking a generally accepted approach for service modeling. Conceptual IT service model designs focus in-depth on describing the individual characteristics of a single ICT service [4]. To date, little agreement exists on a generally accepted approach to the conceptual modeling of ICT services.

The conceptual service model is a core concept used in the management of ICT services [8], [9]. From a practitioners' perspective, having a conceptual understanding of the service design knowledge is the foundation for service management. ICT managers need to know which resources are needed to provide services, and how those resources are being interlinked. To manage the entire portfolio of ICT services efficiently, companies require a conceptual service model to replicate and reuse the same conceptual ICT model across services. By using a conceptual approach to service modeling, the service managers actively manage the ICT service design requirements. Such a holistic and transparent approach to service knowledge management is one key capability that has to be shared across the service lifecycle.

Through an explorative study, the authors wish to find how modularity can be applied in the field of service design. Therefore, this paper analyses ICT service models published in the literature or used by companies and investigates how modularity principles have been applied.

The following sections present and define the main concepts that provide the theoretical background for this research. The authors present a short overview of ICT service characteristics, the conceptual modeling of services, and service modularity.

\section{A. ICT Service Characteristics}

Service-focused ICT management includes the management of ICT services over the services' lifecycle stages: Service strategy, service design, service operation, and service transition [10]. Every lifecycle phase of an 
ICT service uses individual processes, technology assets, activities, functions, vendors and key roles to contribute to the value creation [3]. Matzner et al. (2019) confirm that the complexity in services arise from the interaction of people, processes, technology, and shared information, and presents foundational characteristics of services [11].

Even though ICT services are complex, ICT service design is quite homogeneous across companies and industries. Voss and Hsuan (2009) identified reasons why modularity so far has received little attention in the research community: The heterogeneity of services is one of the main research challenges when designing service studies [12]. Heterogeneity of services means that the variety of services is very high, both within the service portfolio of an individual firm, as well as within and across industries. Researching heterogeneous services poses a challenge for researchers to propose generalizable theories, frameworks, and methods.

\section{B. Conceptual Modeling of Services}

Conceptual models represent how we understand an ICT service's structure, definition, and scope. As service modeling demonstrates resource requirements for ICT service operations, a conceptual service model is a prerequisite for knowledge management and competitive advantage, according to the resource-based view of the firm. A conceptual model, as the name says, is an abstract representation composed of concepts, allowing for generalization and replicability of the model. A conceptual service model should be designed to represent multiple different services. By the construction of a service model, the service designers define the rules of a service's construction, and functionality. In principle, knowledge from organizational units or employees will be made explicit through the model, as the model is an abstract and reusable representation of service knowledge. This example summarizes the importance of ICT service models for complexity management.

The conceptual ICT service model is key to ICT service management. For example, the model is a prerequisite for designing IT systems and processes that support ICT service management at firms. The IT service catalogue is a core IT knowledge management system used in firms for ICT service management [9], [13]. Nissen et al. (2015) analyzed generic IT service catalog structures and analyzed how conceptual ICT service design and catalogue design interlink [14]. Nissen et al. (2015) focused mainly on the balance between ICT model for the service provider and ICT model for the service customer, and the granularity of the ICT service [14]. To design a knowledge management system, practitioners presuppose a conceptual ICT service definition and model [9]. This example outlines the importance of suitable conceptual ICT service models for ICT service management.

To summarize, conceptual ICT service models are key to ICT complexity management and service management.

\section{Service Modularity}

We argue that complex ICT services can be analyzed and managed by using modularity. Modularity refers to the scheme by which interfaces shared among components in a given product architecture are standardized and specified to allow for greater reusability and commonality [15]. Complex systems that are characterized by organized simplicity, can be broken into non-interacting systems. The use of modularity decomposes complex service systems into sub-systems. Consequently, such independent sub-systems can be analyzed separately through the use of analytical reduction [16]. Therefore, the analysis of decomposed complex systems is a successful complexity management strategy. Organized simplicity assumes that a service can be separated into modules, that the modules of one service can be analyzed separately, that principles govern the interconnections of modules and that functions describe the functionalities of modules [17].

Architectural principles such as modularity provide a framework for design knowledge management [5]. Modularity improves design knowledge management effectiveness and efficiency through the abstraction, improvement, and conceptualization of design knowledge. For example, the use of modularity principles and the object-oriented modeling of the product range simplifies the representation of a companies' complex product knowledge [6]. In service design, the application of conceptual modeling captures new architectural knowledge, e.g., improved interface specifications [7], resulting in improved service design knowledge. Consequently, knowledge management effectiveness and efficiency reduce service design complexity.

While the concepts of product architectures and modularity are well established in the engineering and product design literature, the application of architectures and modularity to services has received little attention in services. One research challenge mentioned by Voss and Hsuan (2009) is the fact that services can be understood as either processes or products [12]. Debate continues how the knowledge from the product design literature and process design literature can be applied to services.

The study of modularity covers five dimensions: Interfaces, degree of coupling, components and systems, commonality sharing, and platform [12]. For the conceptual modeling of ICT services, the representation of interfaces and the components and systems is the most important aspect. Interfaces can be defined as standardized linkages shared across components. The purpose of an interface is the governance of arrangement, interconnections, and interdependence of elements [18]. To assess the use of modularity concepts in the ICT models, variables and measurement criteria have been chosen. Table I shows the variables and measurement criteria we chose to assess the modularity dimensions of an ICT service model. 
TABLE I

EVALUATION CRITERIA FOR MODULARITY IN ICT SERVICES

\begin{tabular}{|c|c|c|}
\hline $\begin{array}{l}\text { Modularity } \\
\text { dimension }\end{array}$ & Variable & Measurement \\
\hline \multirow[t]{3}{*}{ Modules } & Component types & Qualitative description \\
\hline & Attributes & Available / not available \\
\hline & Functions & Available / not available \\
\hline \multirow[t]{3}{*}{ Interfaces } & $\begin{array}{ll}\text { Classification } & \text { of } \\
\text { interfaces } & \\
\end{array}$ & Available / not available \\
\hline & Intra-service interface & Available / not available \\
\hline & Inter-service interfaces & Available / not available \\
\hline \multicolumn{3}{|l|}{$\begin{array}{l}\text { Process } \\
\text { dimension }\end{array}$} \\
\hline \multirow[t]{2}{*}{ Process } & Process description & Available / not available \\
\hline & $\begin{array}{l}\text { Interface between } \\
\text { process and technical } \\
\text { components }\end{array}$ & Qualitative description \\
\hline
\end{tabular}

\section{Summary of the Theoretical Grounding and Research Agenda}

According to Wacker, 1998, theory consists of four components: Definition of concepts or variables, a domain in which the theory can be applied, a set of relationships and a prediction [19]. The constructs used in this study are service modularity and the conceptual ICT service model. Theoretical knowledge on the use of modularity in conceptual ICT service models is especially beneficial and applicable to the domain of ICT management. Our research objective is to understand how we can use modularity for the modeling of ICT services for knowledge management purposes. This study uses an explorative case study approach.

Section 2 explains the methodology used for this research. Section 3 presents the results on which ICT modularity principles we found in conceptual ICT service models. Section 4 discusses our findings. Section 5 concludes.

\section{METHODOLOGY}

This explorative case study describes how modularity enables the conceptual modeling of ICT services. The unit of analysis of this case study is the conceptual model of an ICT service. The reason for why this research focusses on ICT services is threefold: First, ICT services are quite comparable across industries, as ICT services are built through the use of similar component types: Software applications, databases, server, storage, network. Second, the service-oriented paradigm is well established in ICT management literature. The ICT management literature has widely focused on the use of service-oriented architectures for understanding ICT services, and the service modularity has been applied to software design [20]. Third, ICT services are complex services that are subject to complexity reductions [4].

We followed the case study method to investigate the research problem. In the following, we explain (1) why we use the case study method, (2) how we conducted a case study, and (3) what empirical data we used for this study.

1) The motivation for the Use of Case Study: Four reasons motivated the choice of the case study methodology for this research [21]. First, the case study answers research questions such as "how" and "why", and the case study method, therefore, fits perfectly to the research question of this research. Second, case studies allow for in-depth studies of the unit of analysis. To identify the often poorly formalized modeling challenges in ICT services, we need to conduct an in-depth study to investigate this phenomenon. Third, the case study method lets us enrichen the empirical discussion by using both primary and secondary data sources. Fourth, to increase the diversity of the empirical evidence of this study, as well as the generalizability towards theory, the case study method allows us to selected multiple cases. The sampling and case selection followed the multiple case study design. To diversify the cases, we chose one case from academia, best practice frameworks, and industrial case studies.

2) Research Design: The case study approach was structured into four different phases: Literature review, research protocol design, data gathering, analysis [22]. First, we conducted a structured literature review. The review presented the current academic discussion on modularity in service management. The review defined the theoretical concepts (service modularity and the conceptual ICT service model) that build the theoretical background for this research. Second, we derived evaluation guidelines for the assessment of the use of modularity principles in conceptual IT service models from our literature review. Those guidelines acted as the framework of our research protocol. The chosen evaluation criteria are presented in Table I. Third, we gathered empirical evidence for this case study. Fourth, we coded and analyzed the empirical cases by using the evaluation criteria defined by the research protocol.

3) Empirical Data: Both primary and secondary data sources have been analyzed. Three empirical cases build the empirical base for this Research. Table II shows the three cases.

TABLE II

CASE OVERVIEW

\begin{tabular}{|l|l|l|}
\hline Case & Type & Reference \\
\hline 1 & $\begin{array}{l}\text { Standards and best } \\
\text { practice }\end{array}$ & {$[8]$} \\
\hline 2 & Literature case & {$[23]$} \\
\hline 3 & Industry case & Fig. 1 \\
\hline
\end{tabular}


Case 1: Best practice case. Standards and best practice frameworks (secondary data), more specifically the ITILC) V3 (Information Technology Infrastructure Library) provided an ICT service model example. We selected this case because we assumed that best practice ICT models have been widely adopted in the ICT service management domain and have been designed by practitioners and domain experts.

Case 2: Literature case. During a structured literature search, we retrieved published research articles (secondary data) that present the use and structure of conceptual ICT service models. We selected a case from the academic literature as we assumed that academic cases would most likely publish conceptual ICT models that have been built with theoretical concepts such as modularity in mind.

Case 3: Industry case. Investigating one service model of an IT department (primary data) allowed us to study ICT service models in their natural context. Fig. 1 shows the conceptual ICT service model used by the case company.

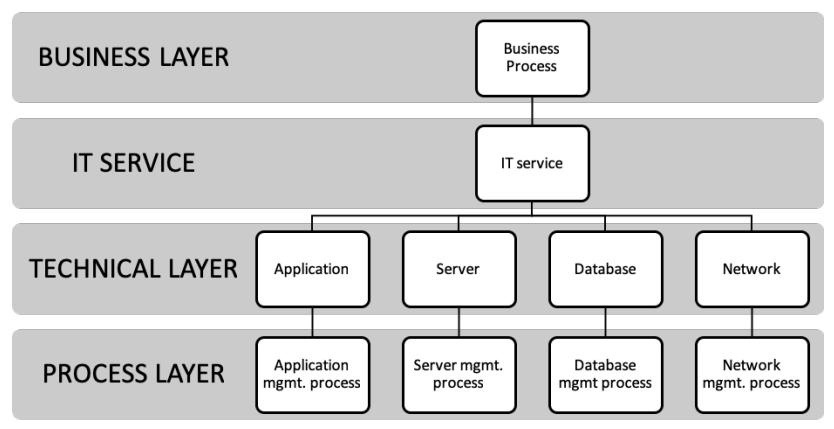

Fig. 1 Conceptual ICT service model used by the case company

We analyzed the three ICT models of cases $1-3$ by using the evaluation framework presented in Table I. We also conducted a cross-case analysis. The following section presents our results.

\section{RESULTS}

Table III shows the use of modularity principles in the investigated ICT service models. The following subsections summarize the results for the cases.

1) Use of modularity principles in ICT service models: While case 1 and case 3 make use of very similar service components, case 2 displays abstract modules and elements. Case 1 and 3 display a wide range of technical and non-technical components. All cases show intraservice interfaces but none of the cases describes those interfaces further nor classifies the interfaces.

2) No use of modularity principles in conceptual ICT service models: None of the cases showed information about the detailed attributes or functions describing the modules, as well as a classification of interfaces. None of the ICT service models displayed inter-service relationships. The lack of characterization of interfaces means that the ICT service model does not further describe the relationship between assets (for instance between software and server) and between service and technical asset (for instance between service and application).

3) The Use of Process Modeling in conceptual ICT Service Models: Two of the ICT service models (case 1 and case 3 ) included the modeling of service management processes (e.g. application management process or server management process) in their service model. In case 3 , the display of the service management process has been modularized, while in case 1 , just one process component serves as a representation of all the service management processes. One important insight from the case study is that the ICT models show both the business processes that use the IT service and the IT service management processes that manage the service. Our findings show the relevance for representing the business-ICT service alignment and the service management processes in a conceptual ICT model.

\section{DISCUSSION}

The results of the case study show that some modularity principles are widely used in conceptual ICT service models while other modularity principles are not at all used. The section discusses the results' implications for research and practitioners further.

The results of this study indicate that ICT service models make use of modularity principles to some extent. The ICT service model represents a high number of components of the ICT service. To some extent, those components are modular and consequently share similar data across components.

TABLE III

RESULTS: MODULARITY PRINCIPLES PER CASE

\begin{tabular}{|c|c|c|c|}
\hline Variable & $\begin{array}{l}\text { Case 1: } \\
\text { Best practice case }\end{array}$ & $\begin{array}{l}\text { Case 2: } \\
\text { Literature } \\
\text { case }\end{array}$ & $\begin{array}{l}\text { Case 3: } \\
\text { Industry case }\end{array}$ \\
\hline $\begin{array}{l}\text { Component } \\
\text { types }\end{array}$ & $\begin{array}{l}\text { Business process } \\
\text { Service } \\
\text { Infrastructure } \\
\text { Environment } \\
\text { Data } \\
\text { Application } \\
\text { One service mgmt. } \\
\text { process for all } \\
\text { technical } \\
\text { components }\end{array}$ & $\begin{array}{l}\text { Service } \\
\text { Module } \\
\text { Element }\end{array}$ & $\begin{array}{l}\text { Business } \\
\text { process } \\
\text { Service } \\
\text { Application } \\
\text { Server } \\
\text { Database } \\
\text { Network } \\
\text { One service } \\
\text { mgmt. process } \\
\text { per technical } \\
\text { component }\end{array}$ \\
\hline $\begin{array}{l}\text { Attributes } \\
\text { Functions } \\
\begin{array}{l}\text { Classification } \\
\text { of interfaces }\end{array} \\
\end{array}$ & \multicolumn{3}{|c|}{ Not available } \\
\hline $\begin{array}{l}\text { Intra-service } \\
\text { interface }\end{array}$ & & & \\
\hline $\begin{array}{l}\text { Inter-service } \\
\text { interfaces }\end{array}$ & \multicolumn{3}{|c|}{ Not available } \\
\hline
\end{tabular}


The use of modular components in conceptual ICT service modules allow firms to leverage the benefits of abstraction and conceptualization of service design knowledge.

Our study suggests that ICT service components are homogeneous across ICT services. The homogeneity furthers the generalizability of conceptual ICT metamodels. ICT management and research can benefit from such standard models that can be used cross-industry.

This study did not find evidence for the use of certain other modularity principles. While the ICT service models feature a high number of components or modules, the ICT service model does not further describe the component attributes and functions. The ICT service models do not further describe the interfaces between and within ICT service modules or components. Logically, a classification of interfaces in ICT services is also missing. Consequently, firms that use those ICT service models do not make use of all the modularity principles and may not be able to leverage the suggested benefits of modularity. Missing use of modularity principles leads to a lack of design knowledge. Missing inter-service interface knowledge leads to lack of knowledge about the relationships between the services within one service portfolio. Missing intra-service interface knowledge results in a lack of knowledge about the relationships between the components of a specific ICT service. Modularity is an approach for the simplification of a company's service design. As a result, the use of ICT service models without a featured representation of service interfaces may not allow firms to actively reduce service complexity through the use of modularity principles.

Surprisingly, the study showed that ICT service models consider not only technical components of the service but also integrates process modeling into the conceptual ICT service model. This study corroborates the ideas of [4], which suggests to design IT service models based on multiple design criteria, including service process mapping. Our study suggests that service process modeling is an essential feature of a conceptual ICT service model.

\section{CONCLUSION}

This study showed that modularity principles enable the usefulness and conceptualization of ICT models. The study generated qualitative insights in the way how modularity principles can be used for the modeling of ICT services. For future research, we recommend researching the ICT service modeling process and the application of modularity in the ICT service area.

\section{REFERENCES}

[1] M. A. Winniford, S. Conger, and L. Erickson-Harris,

"Confusion in the ranks: IT service management practice and terminology," Information Systems Management, vol. 26, no. 2, pp. 153-163, 2009.
[2] J. Iden and T. R. Eikebrokk, "Implementing IT Service Management: A systematic literature review," International Journal of Information Management, vol. 33, no. 3, pp. 512523, 2013.

[3] N. Shahsavarani and S. Ji, "Research in Information Technology Service Management (ITSM) (2000-2010): An overview," International Journal of Information Systems in the Service Sector, vol. 6, no. 4, pp. 73-91, 2014.

[4] H. Kattenstroth and D. Heise, "Towards a method for IT service management," in IFIP Working Conference on The Practice of Enterprise Modeling, 2011, pp. 178-192.

[5] S. A. Brax, A. Bask, J. Hsuan, and C. Voss, "Service modularity and architecture - an overview and research agenda," International Journal of Operations and Production Management, vol. 37, no. 6, pp. 686-702, 2017.

[6] T. Tuunanen, A. Bask, and H. Merisalo-Rantanen, "Typology for modular service design: review of literature," International Journal of Service Science, Management, Engineering, and Technology (IJSSMET), vol. 3, no. 3, pp. 99-112, 2012.

[7] L. Hvam, Z. N. L. Herbert-Hansen, A. Haug, A. Kudsk, and N. H. Mortensen, "A framework for determining product modularity levels," Advances in Mechanical Engineering, vol. 9, no. 10,2017

[8] L. Hunnebeck, C. Rudd, and S. Lacy, "ITIL Service Design," TSO, London, 2011.

[9] F. Schorr and L. Hvam, "The Use of Design-science to Define Information Content Requirements for IT Service Catalogs," IEEE International Conference on Industrial Engineering and Engineering Management, pp. 497-501, 2019.

[10] I. C. B. Office of Government Commerce (OGC), Service Design. TSO, 2007.

[11] M. Matzner et al., "Digital Transformation in Service Management," Journal of Service Management Research, vol. 2, no. 2, pp. 3-21, 2018.

[12] C. A. Voss and J. Hsuan, "Service Architecture and Modularity," vol. 40, no. 3, pp. 541-569, 2009.

[13] F. Nord, R. Dörbecker, T. Böhmann, R. Dorbecker, and T. Bohmann, "Structure, content and use of it service catalogs empirical analysis and development of a maturity model," Proceedings of the Annual Hawaii International Conference on System Sciences, vol. 2016-March, pp. 1642-1651, 2016.

[14] V. Nissen, D. Jung, M. Petsch, and C.-P. Präg, "Recommendations for a general IT Service Catalogue structure," Enterprise Modelling and Information Systems Architectures, vol. 10, no. 1, pp. 89-108, 2015.

[15] M. A. Schilling, "Toward a general modular systems theory and its application to interfirm product modularity," Academy of management review, vol. 25, no. 2, pp. 312-334, 2000.

[16] G. Weinberg, An Introduction to General Systems Thinking. John Wiley, 1975.

[17] N. G. Leveson, Engineering a Safer World: Systems Thinking Applied to Safety, 1st ed. Cambridge, MA: The MIT Press, 2011.

[18] ESD Architecture Committee, "The influence of architecture in engineering systems," MIT Engineering Systems Monograph. Cambridge, MA: Massachusetts Institute of Technology, 2004.

[19] J. Wacker, "A definition of theory: research guidelines for different theory-building research methods in operations management," Journal of Operations Management, vol. 16, no. 4, pp. 361-385, 1998 .

[20] A. Bask, M. Lipponen, M. Rajahonka, and M. Tinnilä, "Framework for modularity and customization: service perspective," Journal of Business \& Industrial Marketing, vol. 26, no. 5, pp. 306-319, 2011.

[21] R. K. Yin, Case study research and applications: Design and methods. Sage publications, 2017.

[22] C. Karlsson, Research Methods for Operations Management, Second Edi. Routledge, 2016.

[23] S. Rudolph, "Servicebasierte Planung und Steuerung der ITInfrastruktur im Mittelstand," Ein Modellansatz zur Struktur der IT-Leistungserbringung. Gabler, Wiesbaden, 2009. 